\title{
Should homosexuals be vaccinated against hepatitis $B$ virus? Cost and benefit assessment
}

\author{
MICHAEL W ADLER, ELIZABETH M BELSEY, J ALLEN MCCUTCHAN, ADRIAN MINDEL
}

\begin{abstract}
The recent introduction of a vaccine against hepatitis $B$ has raised the questions of who should be offered it and what the cost would be of a vaccination programme. An analysis was performed of the financial costs and benefits of such a programme designed to prevent acute hepatitis $B$ in male homosexuals in the United Kingdom. Under various assumptions the total costs of screening and vaccination ranged from $£ 2 \cdot 2 \mathrm{~m}$ to $£ 3 m$ for a five year programme and from $£ 3.3 \mathrm{~m}$ to $£ 4.8 \mathrm{~m}$ for a 10 year programme. The benefits over the same two periods for the programme, depending on two different assumptions of mortality prevented, ranged from $£ 3.9 \mathrm{~m}$ to $£ 13.7 \mathrm{~m}$ and from $£ 7 \mathrm{~m}$ to $£ \mathbf{2 4 . 4 m}$. Thus considerable savings may be made to the national economy by offering vaccination to homosexuals. These savings are obtained after consideration of only the acute aspects of hepatitis B. Had it been possible to determine the costs of the chronic sequelae of this disease the savings, compared with the costs, would have been greatly increased.
\end{abstract}

\section{Introduction}

The recent successful controlled trial of hepatitis B vaccine among homosexuals in New York has raised the possibility of the widescale preventative use of such a vaccine. ${ }^{1}$ It would be of most use in developing countries with high carrier rates of hepatitis B surface antigen ( $\mathrm{HBsAg}$ ), but it has become commercially available initially in America, the United Kingdom, and other developed countries. A few courses of the vaccine were released in the United Kingdom at the end of September 1982. The official guidelines issued by the Department of Health and Social Security suggest restricted use to high risk health care personnel, some patients, and family contacts. ${ }^{2}$ Even though supplies are limited they are available privately and eventually will become more freely available. A clear policy for the future is necessary. Unless this is established some people will be immunised unnecessarily whereas others at high risk will not, with a resulting unnecessary cost to the National Health Service. In view of this it is desirable and necessary that the costs and benefits of vaccination are calculated.

We have examined the financial costs and benefits of a vaccination programme to prevent acute hepatitis B in male homosexuals in the United Kingdom, a group of patients at particular risk of hepatitis B who have not been designated at high risk in the DHSS guidelines. ${ }^{3-6}$ Members of this group are now numerous, high users of sexually transmitted disease services, and the main contributors to the increase in hepatitis B diagnosed in sexually transmitted disease clinics.

\section{Methods}

The analysis was performed for two programmes, one lasting five years and one 10 years. Future costs and benefits were discounted at an annual rate of $5 \%$ (Treasury recommended rate) and 1981 prices were used throughout. Much of the information required to perform 
the cost-benefit analysis was unreliable or unavailable, and values had to be assumed for several variables, such as patient uptake of the vaccine and the proportion of cases that would be prevented. All the economic data are based on available averages. This means that the results presented are indicative of costs and benefits rather than definitive. To ensure that the final outcome would be conservativethat costs would not be underestimated or benefits overestimatedhigh values were assumed for all variables that affected the costs of the programme and low values for variables that affected the benefits. In addition, both costs and benefits were calculated for a range of possible values of some variables.

\section{Results}

\section{NUMBER OF HOMOSEXUALS}

There are no accurate figures on the number of homosexuals in the United Kingdom. In the Wolfenden report it was estimated that $5 \%$ of the male population were homosexuals. ${ }^{7}$ Using the proportion of $5 \%$ the estimated current number of homosexuals aged 20-64 years would be $6908100^{8}$ This figure is an overestimate of the number of homosexuals at risk of contracting hepatitis, since many of them will have stable relationships with one partner.

Costs were therefore calculated on the assumption that vaccination would be made available to any homosexual male patient who attended a sexually transmitted disease clinic during the programme. In a study of patients seen in clinics in 1978 about 18000 male homosexuals attended clinics in England and Wales. ${ }^{9}$ Since the number of cases treated in clinics rises yearly, and to account for homosexuals attending clinics in Scotland and Northern Ireland, the figure to be used in this analysis was set at 20000 .

\section{Costs}

Before vaccination-for reasons of cost effectiveness-patients would be screened for their immune status with regard to hepatitis $B$ virus ${ }^{1011}$ by determining protective concentrations of serum antibody to hepatitis B surface antigen (anti-HBs $>0.05 \mathrm{IU} / \mathrm{ml}$ ). Screening and vaccination would be made available to all homosexual male patients who visited a clinic for the first time during the programme. Initially, all patients would require screening, but as the programme progressed an increasing proportion of homosexual male attenders would have been screened already. In the study of clinic patients in $197846 \%$ of male homosexuals had made one or more previous visits to the clinic where they were sampled, while the remaining $54 \%$ were "new" patients (Belsey EM, unpublished observation). For the cost-benefit analysis the proportion of patients attending a clinic who would be "new" to that clinic was assumed to be $50 \%$ or $70 \%$. In addition, it was assumed that the backlog of "old" patients would be cleared over five years. Table I shows the number of patients who would have to be screened, depending on the assumption made about the proportion of "new" patients. The cost of screening was

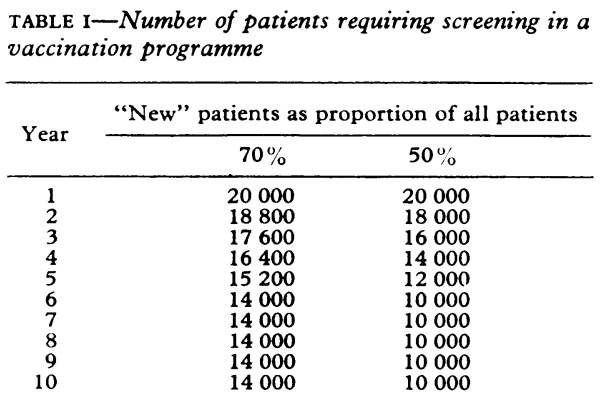

calculated at $£ 5$ a patient; this covers equipment costs and staff time (reagents $£ 3 \cdot 50$, time $£ 1 \cdot 50$ ).

It was assumed that $50 \%$ of patients screened would be immune to hepatitis B virus. (In fact, as the programme proceeded this figure would probably rise, since a proportion of the "new" patients attending any one clinic would already have been vaccinated at some other clinic.) Vaccination would then be offered to the remaining patients. The cost of the vaccine alone was taken to be $£ 63.50$ a person (this will vary with the dollar exchange rate) and uptake was assumed to be high- $80 \%$ or $100 \%$.

On these assumptions the total costs of screening and vaccination would range from $£ 2 \cdot 2 \mathrm{~m}$ to $£ 3 \mathrm{~m}$ for a five year programme and from $£ 3 \cdot 3 \mathrm{~m}$ to $£ 4 \cdot 8 \mathrm{~m}$ for a 10 year programme (table II).

TABLE II-Costs of a five and 10 year vaccination programme against hepatitis $B$ in male homosexuals

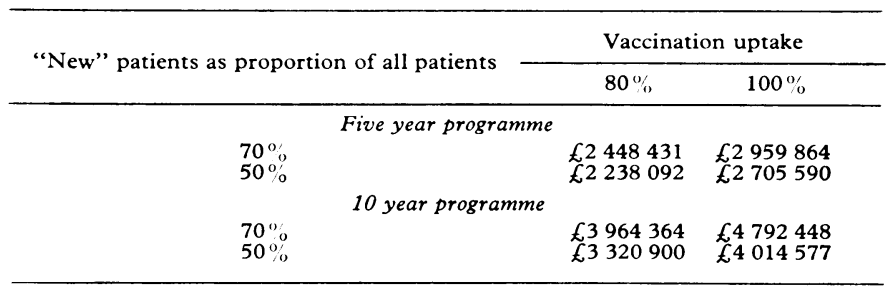

\section{BENEFITS}

To calculate the immediate financial benefits of the programme it is necessary to know the annual number of cases of acute hepatitis $B$ in homosexuals in the population. A survey of clinical cases of hepatitis in three London boroughs (Hounslow, Richmond, and Ealing) between 1972 and 1975 provides the only reliable population based data $^{12}$ : 489 cases were found, of which 455 were tested for hepatitis B surface antigen (HBsAg) by radioimmunoassay and 93 were positive. Thus, an annual incidence can be calculated of 4.9 cases of acute hepatitis B per 100000 . (This compares with an incidence of 4.7 per 100000 based on laboratory reports of patients with confirmed hepatitis B sent to the Communicable Disease Centre from the same area. $)^{13}$ Sixty nine cases of acute hepatitis $B$ occurred in men, of whom $28(41 \%)$ were either self declared (11) or "strongly suspected" (17) homosexuals. The annual incidence of hepatitis B in homosexuals in this population of 682695 persons was thus 1.47 per 100000 . Applying this rate to the population of the United Kingdom results in an estimated incidence in homosexuals of 810 cases a year.

Although the population surveyed may not be typical of the United Kingdom there is no reason to assume that it is appreciably atypical with respect to hepatitis or homosexuality. We have, however, attempted to obtain other population based incidence figures but with only limited success. Polakoff and Tillett analysed the number of patients with confirmed hepatitis $B$ reported by laboratories. ${ }^{13}$ Over five years (1975-9) there were 5282 cases in both sexes (3574 men, 1630 women). Only 82 of the patients were clearly identified as homosexuals, although a further 217 cases were acquired through sexual exposure and most of these are likely to have been homosexually acquired. In half of all the reported cases no clinical or other details were obtained, and it is likely that more of these patients were homosexual. Furthermore, not all cases of clinical hepatitis are notified by the attending doctor or laboratories, and finally at least half of the infections are anicteric and may never be presented for medical care and are thus not notified. In the population based study performed by Stewart and his colleagues homosexuals accounted for $41 \%$ of male cases, ${ }^{12}$ and if we assume the same proportion for the laboratory reported cases the annual incidence of homosexually acquired cases of hepatitis B is 290 . This compares with 810 cases derived from the population based study. ${ }^{12}$ Thus to ensure that the benefits of the programme would not be overestimated we based our calculations on 250 and 500 cases a year.

\section{Primary and hospital care}

The financial benefits of preventing cases of acute hepatitis $B$ would derive from three sources: savings in inpatient hospital care $\mathbb{D}$

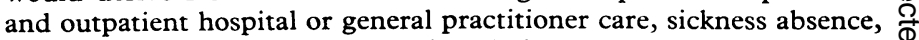
and premature deaths. Stewart found that $48 \%$ of cases were ad- $\unrhd$ mitted to hospital. ${ }^{12}$ Again, in order not to overestimate $30 \%$ was used in the calculation of potential benefits. The average number of days $\Omega$ in hospital per case of hepatitis was 12.8 in 1980 (unpublished $\frac{O}{0}$ data, hospital inpatient inquiry, 1980), whereas the current cost of a day's stay in hospital is $£ 72 \cdot 32^{14}$ (adjusted from 1980 figures). This means that the average cost of inpatient care per case may be estimated 
as $£ 0.30 \times £ 12.8 \times £ 72.32=£ 277 \cdot 71$. Thus if there are 250 cases of acute hepatitis $B$ in male homosexuals each year the total cost of inpatient care would be $£ 69428$ and for 500 cases $£ 138855$.

It was assumed that each patient would make at least one outpatient visit after discharge from hospital, while those treated in general practice would receive or make visits costing an equivalent sum. This assumption of only one visit is likely to be very conservative. If the current cost of an outpatient visit is taken to be $£ 19.91$ (adjusted from 1980 figures $)^{14}$ then the cost of outpatient/general practice care for 250 cases is $£ 4978$ a year, while for 500 cases it is $£ 9955$ a year.

\section{Sickness absence}

In the year ended March 1980 a total of 375600 working days were lost owing to illnesses in the whole of International Classification of Diseases category 573 (DHSS, unpublished data). Category 573 includes hepatitis due to various infectious and non-infectious agents and other rare hepatic conditions. It was not possible to separate viral hepatitis from these other disorders when calculating working days lost. We felt justified in lising the whole of category 573 in our calculations since viral hepatitis will be the major, if not almost the exclusive contributor to days lost in this category. There were 3203 cases of acute hepatitis in $1979 . .^{15}$ An estimate of the number of working days lost per case is therefore given as 375600 divided by $3203=117 \cdot 3$ days. The mean daily earnings for men were $£ 27$ in $1981 .{ }^{16}$ If there are 250 cases of acute hepatitis $B$ in male homosexuals cach year the cost of associated sickness absence is therefore estimated to be $£ 791539$ a year, whereas if there are 500 cases the cost will be $£ 1583078$ a year.

\section{Premature deaths}

In 1980 there were 30 deaths in men due to acute hepatitis B (unpublished data, Office of Population Censuses and Surveys). Stewart found that homosexuals accounted for 28 out of 69 cases of hepatitis $B$ in men. ${ }^{12}$ Thus the number of premature deaths in homosexual men due to hepatitis $B$ may be estimated as $30 \times 28 / 69=$ $12 \cdot 17$ annually. Since the current cost of a premature male death is estimated at about $£ 132700^{17}$ the total cost of such deaths amounts to $£ 30 \times 28 / 69 \times 132700=£ 1615478$ a year. It is possible that some of the 30 deaths attributed to acute hepatitis in 1980 were in fact chronic and that this figure is too high. The Centers for Disease Control in the United States give a case fatality of $1 \cdot 1 \%$ for cases of HBsAg positive hepatitis. ${ }^{18}$ This figure has been used to make alternative estimates of the costs attributable to deaths. Thus depending on the number of cases a year $(250$ or 500$)$ the cost of associated deaths ranges from $£ 364925$ to $£ 729850$ a year.

\section{Analysis of savings}

The analysis of immediate financial benefits which would accrue from a vaccination programme was carried out under the assumptions that $70^{\circ}$, or $90 \%$ of cases of hepatitis $\mathrm{B}$ in homosexual men would be prevented for the duration of the programme. Table III shows the immediate savings that would result from five and 10 year vaccination programmes for a mortality of 12 cases a year or an annual case fatality of $1.1 \%$. The immediate savings from a five year programme would range from $£ 7.9 \mathrm{~m}$ to $£ 13.7 \mathrm{~m}$ for an annual mortality

TABLE III-Financial benefits of a five and 10 year vaccination programme against hepatitis $B$ in male homosexuals

\begin{tabular}{|c|c|c|c|}
\hline \multirow{2}{*}{ Mortality assumed (per year) } & \multirow{2}{*}{ Cases prevented $(\%)$} & \multicolumn{2}{|c|}{ No of cases per year } \\
\hline & & 250 & 500 \\
\hline \multicolumn{4}{|c|}{ Five year programme } \\
\hline $\begin{array}{c}12 \text { cases } \\
1 \cdot 1 \%\end{array}$ & $\begin{array}{l}90 \\
70 \\
90 \\
70\end{array}$ & $\begin{array}{r}£ 10152379 \\
£ 7896295 \\
£ 5035922 \\
£ 3916829\end{array}$ & $\begin{array}{r}£ 13695261 \\
£ 10651869 \\
£ 10071842 \\
\wp 7833654\end{array}$ \\
\hline \multicolumn{4}{|c|}{10 year programme } \\
\hline $\begin{array}{c}12 \text { cases } \\
1 \cdot 1 \%\end{array}$ & $\begin{array}{l}90 \\
70 \\
90 \\
70\end{array}$ & $\begin{array}{r}£ 18107034 \\
£ 14083249 \\
£ 8981699 \\
£ 6985767\end{array}$ & 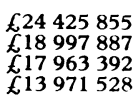 \\
\hline
\end{tabular}

of 12 cases and for a case fatality of $1.1 \%$ from $£ 3.9 \mathrm{~m}$ to just over $£ 10 \mathrm{~m}$. For a 10 year programme the respective figures would be $£ 14.1 \mathrm{~m}$ to $£ 24 \cdot 4 \mathrm{~m}$ and $£ 7 \mathrm{~m}$ to just under $£ 18 \mathrm{~m}$

\section{Discussion}

The calculations given here indicate that substantial savings can be made to the national economy by offering vaccination to homosexuals against hepatitis B. The 10 year programme would yield benefit to cost ratios of between $1.46(70 \%$ new patients, $100 \%$ uptake, 250 cases a year, $70 \%$ cases prevented, $1.1 \%$ a year mortality) and $7.36(50 \%$ new patients, $80 \%$ uptake, 500 cases a year, $90 \%$ cases prevented, 12 deaths a year). A recent American study also confirmed that vaccination of homosexuals would result in a reduction in the costs of medical care. ${ }^{10}$

We have purposely confined our benefit estimates to the acute aspects of hepatitis B. No allowance for longer term financial benefits has been made in this analysis: firstly, because the incidence and associated costs of the complications of hepatitis $B$ in homosexual men (chronic persistent and active hepatitis, cirrhosis, and hepatocellular carcinoma) cannot be estimated with any precision; and, secondly, because the benefits would not be realised for about 20 years. Had we felt able to carry out similar calculations for the chronic sequelae there is no doubt that the savings, compared with the costs of vaccinating homosexuals, would be greatly increased. At present there are several estimates of the proportion of individuals progressing from acute to chronic liver disease. ${ }^{19-23}$ Unfortunately, none of these figures relates to sexually acquired hepatitis B in homosexuals, the natural history of which may be different.

There are two other potential benefits of vaccination that have not been costed in this paper. The first is the external benefits to contacts of the vaccinee, some of whom would, in the absence of vaccination, themselves become infected. A case generation model would be required to obtain such data. Another aspect not considered is that of intangible benefit-for example, freedom from anxiety about contracting hepatitis $B$ that a vaccinated person would experience.

At present the length of protection offered by vaccinationand thus the need, or otherwise, for booster doses-is not known. Thus we have not costed this possible component of a vaccination programme. Certainly, the costs will increase should revaccination be required but the benefits will also be prolonged, since at present our calculations have taken into account only the acute benefits occurring in the same year as that in which the vaccination occurs.

We consider that there are financial benefits in a vaccination programme for homosexuals, despite our inability to cost the chronic manifestations of the disease or calculate external and intangible benefits. This positive economic outcome does not, however, at the same time imply that the demand for vaccine can be met using existing services. The logistics of a vaccination programme should be defined as soon as possible. Failure to do so will result in a fragmented and costly approach to vaccination. It is clinically important and makes economic sense that homosexual patients are screened for anti-HBs, ${ }^{1011}$ managed, and followed up by those with an expertise in sexually acquired hepatitis and the special problems relating to homosexuals. In the present climate this will not happen in many instances since private and general practitioners will be able to prescribe the vaccine. It is essential - and not too late-before the vaccine is more freely available to develop a rational policy, which is costed and evaluated. We have pointed out that our calculations use available averages and, therefore, do not reflect the precise marginal changes in costs that would accompany the establishment of a vaccination programme for homosexuals. The next stage in considering a vaccination policy requires a careful analysis of actual changes in the use of resources. These calculations will provide more refined estimates, but it is unlikely that the savings indicated in this paper will alter substantially 
once this has been performed. It will be necessary to test and cost the feasibility and consequences of different approaches to vaccination; for example, are sexually transmitted disease clinics the best places for this to be performed and would those working in such clinics be happy to do this ? How would this affect their workload and case mix with the possibility of clinics becoming vaccination centres ? Finally, it will be desirable to perform long term epidemiological studies to assess the benefits, risks, and natural history of disease in those vaccinated against hepatitis B and in the homosexual population as a whole.

We are grateful to Andrew Creese for his advice and criticisms.

\section{References}

${ }^{1}$ Szmuness W, Stevens CE, Harley EJ, et al. Hepatitis B vaccine. Demonstration of efficacy in a controlled clinical trial in a high risk population in the United States. N Engl F Med 1980;303:833-41.

${ }^{2}$ Yellowlees H, Poole AAB. Hepatitis B vaccine: guidance on use. DHSS Letter $1982 ; \mathrm{CMO}(82) 13$.

${ }^{3}$ Fulford KWM, Dane DS, Catterall RD, Woof R, Denning JV. Australia antigen and antibody among patients attending a clinic for sexually transmitted diseases. Lancet $1973 ; \mathrm{i}: 1470-3$.

4 Heathcote J, Sherlock S. Spread of acute type B hepatitis in London. Lancet $1973 ; \mathrm{i}: 1468-70$.

${ }^{5}$ Jeffries DJ, James WH, Jefferiss FJG. Australia (hepatitis associated) antigen in patients attending a venereal disease clinic. $\mathrm{Br} \mathrm{Med} \mathcal{F} 1973$; ii :455-6.

6zmuness W, Much MI, Prince AM, et al. On the role of sexual behaviour in the spread of hepatitis B infection. Ann Intern Med $1975 ; 83: 489-95$.

7 Scottish Home Department. Report of the committee on homosexual offences and prostitution. London: HMSO, 1957.
* Office of Population Censuses and Surveys. Great Britain: regional and national summary. OPCS Monitor. Cen 81 CM57. London: Govern-

ment Statistical Service, 1982 .
${ }^{\circ}$ Belsey EM, Adler MW. Study of STD clinic attenders in England and $\mathbb{D}$ Wales, 1978: 1 Patients versus cases. Br f Vener Dis 1981;57:285-9.

10 Mulley AG, Silverstein MD, Dienstag JL. Indications for hepatitis B vaccine, based on cost effectiveness analysis. $N$ Engl f Med 1982;307: 644-52.

1 Hatzakis A, Anastasakos, C, Hadziyannis S. Hepatitis B vaccination. Lancet 1982 ;ii : 1457-8.

12 Stewart JS, Farrow LJ, Clifford RE, et al. Three year survey of viral \& hepatitis in West London $Q \mathcal{F}$ Med 1978;47:365-84.

13 Polakoff S, Tillett HE. Acute viral hepatitis B: laboratory reports 1975-9. Br Med f $1982 ; 284: 1881-2$.

14 Department of Health and Social Security. Health services costing returns,

year ended 31st March 1980. London: DHSS, 1981 .
15 Office of Population Censuses and Surveys. Infectious diseases, December quarter 1980. OPCS Monitor MB2 81/2. London: Government $\overline{\bar{\omega}}$ Statistical Service.

${ }^{16}$ Department of Employment. New earnings survey 1981. London: HMSO, $\stackrel{ه}{\circledR}$ 1981.

17 Department of Transport. Road accident costs. Highways economics note no 1. (July 1982). London: HMSO, 1981.

${ }^{18}$ Center for Disease Control. Hepatitis surveillance for 1978. Atlanta, GA: Center for Disease Control, March 1981. (Report 46.)

19 Redeker AG. Viral hepatitis clinical aspects. Am f Med Sci 1975;270:9-16.

${ }^{20}$ Bryan JA. Viral hepatitis. 1 Clinical and laboratory aspects and epi- $O$ demiology. Postgrad Med 1980;68:66-76.

${ }^{21}$ Blumberg BS. The hepatitis B virus. Public Health Rep 1980;95:427-35. त

${ }^{22}$ Beasley RP, Lim CC, Hwang LY, Chien CS. Hepatocellular carcinoma and hepatitis B virus. A prospective study of 22707 men in Taiwan. Lancet $1981 ;$ ii : 1129-33.

${ }^{23}$ Hoofnagle JH. Type B hepatitis: virology, serology and clinical course. $\infty$ Seminars in Liver Disease $1981 ; 1: 7-14$.

(Accepted 22 March 1983)
Exercise bicycles have been sold in large numbers over recent years and are obviously used at peak respiratory rate. Many of them use a braking device to give some effort to pedal against, and some of these use pads that look very similar to the asbestos linings used in car brakes. Has anyone investigated whether asbestos fibres are shed in sufficient numbers to be a hazard to health?

I do not know of any investigation into the release of asbestos fibres from brake pads on exercise bicycles. Brake pads, apart from some very specialised uses 40 or more years ago, are made from chrysotile asbestos. The respiratory hazards from exposure to asbestos are fibrosis (asbestosis) and cancer of the lung and mesothelioma. Whereas earlier studies in the asbestos extraction and textile industries showed high excess mortality from these diseases, more recent studies on workers using chrysotile asbestos in the manufacture of cement and friction materials (including brake pads) show no detectable effect on mortality. ${ }^{12}$ Mesothelioma is generally caused by crocidolite and the disease in patients exposed to chrysotile alone are uncommon. One case was, however, reported recently in a brake repair worker, ${ }^{3}$ but it was suggested that his considerable exposure to asbestos occurred not just from handling brake pads but from machining them. Generally, the risk of malignant disease among such workers appears to be quite low, and the risk of asbestos disease from the brake pads of an exercise bicycle, therefore, must be remarkably low.-W R LEE, professor of occupational health, Manchester.

1 Thomas HF, Benjamin IT, Elwood PC, Sweetnam PM. A further follow-up study of workers from an asbestos cement factory. Brf Ind Med 1982;39:273-6. using asbestos. Br $\mathcal{f}$ Ind Med $1983 ; 40: 1-7$

Langer AM, McCaughey WTE. Mesothelioma in a brake repair worker. Lancet $1982 ;$ ii:1101-3.

\section{What is the cause of three month colic in babies?}

The cause of "Three month colic" is unknown. Some $16^{\circ}{ }^{1}$ to $40 \%$ " of babies have episodes in which they cry vigorously, often for several hours in the afternoon or evening, draw up their legs, and go red in the face. It is assumed, but not proved, that they are experiencing abdominal pain. The problem affects first born more often than subsequent children and mothers of higher social class and educational attainment $^{12}$ complain most frequently. Ninety per cent of the babies start having their attacks in the first six weeks of life; nearly half of them have stopped by the age of 3 months and nearly $90 \%$ by 6 months. The most commonly suggested cause is intolerance $\overrightarrow{\hat{O}}$ to cows' milk but the evidence varies: breast fed babies are as vulnerable 3 as bottle fed. ${ }^{1} \mathrm{~A}$ recent American study failed to show evidence of lactose intolerance or allergy to cows' milk protein, ${ }^{3}$ but in Sweden 0 intolerance of cows' milk was found to be common in babies admitted to hospital with colic. ${ }^{4}$ Cows' milk proteins may enter breast milk and restricting the breast feeding mother's intake of milk may relieve the baby's symptoms ${ }^{5}$ but here again other workers have produced 0 conflicting data. ${ }^{6}$ Colic persisting beyond the usual time probably justifies a trial of milk exclusion for either mother or baby. ${ }^{1}$ Many babies intolerant of cows' milk may also be intolerant of soya bean 3 based milks, ${ }^{4}$ and a hydrolised casein milk (Nutramigen) is preferable as a substitute for the usual cows' milk formulas. Thomas has suggested that the incidence of this type of colic is increasing and N that this may be related to changes in obstetric practice, particularly $D$ epidural analgesia and its complications. ${ }^{7}$ Usually, treatment consists을. of explanation and reassurance and a trial of dicyclomine hydrochloride (Merbentyl). These babies tend to be more active in later infancy, ${ }^{2} \mathrm{O}$ and Brazelton has found it useful to tell mothers that colicky babiesw often become active and inquiring toddlers. ${ }^{8}-D$ P ADDY, consultant paediatrician, Birmingham.

Hide DW, Guyer BM. Prevalence of infant colic. Arch Dis Child 1982;57:559-60.\$ Boulton TJC, Rowley MP. Nutritional studies during childhood III. Incidenta?

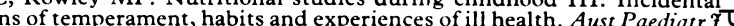
$1979 ; 15: 87-90$.

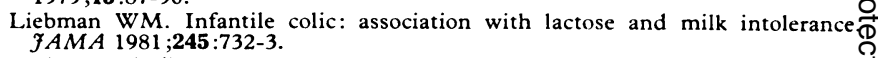

'Lothe L, Lindberg T, Jakobsson I. Cows' milk formula as a cause of infantileक⿱ study. Pediatrics $1982,70.7-10$. Jakobsson I, Lindberg T. Cows' milk as a cause of infantile colic in breast-fedo
infants. Lancet 1978;ii:437.

Evans RW, Fergusson DM, Allardyce RA, Taylor B. Maternal diet and infantilo colic in breast fed infants. Lancet 1981 ; $1: 1340-2$.

Thomas DB. Aetiological associations in infantile colic: an hypothesis. Aus Paediatr F $1981 ; 17: 292-5$.

Brazelton TB. Comment. In: Oski FA, Stockman JA III, eds. Yearbook of pediatric

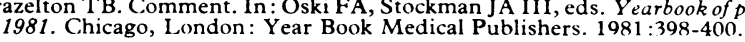

